\section{Menopause and brain function}

Russel L. Thompson slightly raise the risk of certain types of cancer. Women should talk with their doctors about HRT so they can make the best choice for long-term health.

\section{Is there a link between meno- pause and brain function?}

Estrogen is a key element in the work of the brain. It is part of the brain's signaling system. Studies have shown that estrogen helps direct blood to parts of the brain that are more active. The idea that female hormones are needed for the brain to work well is backed up by reports that some have more memory problems after menopause. Also, some studies have found that HRT may make the brain work better.

\section{A test of brain function in menopause}

The authors studied over 800 women every year for 6 years. Only women not on HRT were in the study. The women were given tests of brain function every year. The study's goal was to find out if women in later stages of menopause did worse on tests of brain function.

\section{How to measure loss of brain function?}

Brain function may be measured in many ways. The study by Meyer et al. looked at how fast the women could match figures and reverse a string of numbers from memory. These two tests are often used to find other problems of brain function. To be sure that factors besides menopause did not cause changes, the study included women from different groups. A balance of black and white women was in the study. Also, people in the study had different levels of health, education, and income.

\section{What was found?}

The study looked at change in test scores over 6 years. Scores were compared for women in premenopause, during menopause, and postmenopause groups. If menopause harms brain function, the test scores should have gone down the most for the postmenopause group, less for the group in menopause, and not at all for the group not yet in menopause. But the study did not find that pattern of decline. In fact, most groups improved their scores over time. In those groups that did go down, the size of the decline was so small that it could not be linked to menopause.

\section{What does this mean?}

This study looked at a wide range of women over 6 years and did not find worse brain abilities in women during or after menopause. This finding does not fit with what women have reported about memory loss after menopause. It also does not fit with what we know about estrogen's role in the brain. What does this study mean when we consider these other things we know about menopause? It may be that the brain does not need the hormones as much as we think. Maybe the tests used in study did not measure the brain function that depends on the lost hormones. It may be that the women got better scores on the tests because they practiced taking them. Perhaps their brains were not working as well, but they learned how to take the tests better. More research is needed to answer these and other questions about the effects of menopause on the brain. 


\section{What are the different types of memory?}

Although problems with memory become increasingly common as people age, most people will never develop severe memory problems, or dementia. Memory is a person's ability to remember information. It is commonly divided into three types: short term, long term, and working memory. Short-term memory is a person's ability to remember new information. For example, when directory assistance gives us a telephone number, we may forget it before we try to dial it. Longterm memory refers to the ability to remember things that were learned in the past. For example, some people have problems remembering the name of a person they have not seen for a long time. Short-term memory is affected more by aging than long-term memory.

Working memory involves doing two things at once. Studies show this type of memory is also affected by aging. For example, think about trying to subtract two big numbers in your head. You need to hold the numbers in your memory at the same time that you are making computations involving 'borrowing.' When you focus on the subtraction process, you may forget the original numbers you were working with. This seems to create a drain on your memory capacity, or a kind of overload.

\section{What causes memory loss?}

Scientists who study memory have many ideas about the causes of memory changes with age. Experts agree that memory problems in later life are due to a combination of things. These include chemical changes in the brain that occur with aging, a slowing of the brain's information processing abilities, certain diseases, and the use of certain medications. Another reason may be simple disuse. Table 1 lists common reasons why people have trouble remembering things.
Table 1 Why do I forget? Research indicates several common reasons

Distraction interrupts memory processing

Sensory losses-vision and hearing deficits create information intake problems

Fatigue decreases attention span

Medication may slow mental functioning

Emotion factors (especially anxiety and depression) can interfere with memory

Viewing things as not important reduces motivation to remember

Having a lot to remember creates an overload and concern about our ability to remember

\section{How can I help myself keep a healthy, working memory?} Research shows that many different things affect how well people remember, at any age. If you know what they are, you can often use this information to help your own memory functions. For example, when you are upset, you cannot concentrate well and so may not "learn" what you ultimately want to remember. Sometimes it seems that a person's memory is not working well and the real reason is that they are distracted. For example, if you enter a room to get something and the telephone rings, you may forget what you went into the room for.

Table 2 Helpful hints for remembering things

Write things down (use lists, schedules, etc.)

Put frequently used things in the same place each time

Repeat information that you need to remember over and over again

Rely on placement to trigger your memory (for example, leaving an umbrella on the doorknob)

Review photo albums or yearbooks when you expect to see people after a long absence
When you do not pay attention, you are not likely to register information in the first place. Paying attention takes effort. Think of the times you rush out the door, forgetting something. Perhaps you need to slow down and pause. For example, do you ever wonder whether you have already done something, such as turning the oven off or turning the light out in the basement? To increase your ability to remember, you need to pay attention to what you are doing, so that it will register in your memory.

In one study, researchers found that people were less likely to develop dementia if they participated in some type of leisure time activity. The chances of developing dementia got lower with each additional activity a person participated in. To lower your chances of developing severe memory loss, the more activities you are involved in throughout your life, the lower your risk may be. This suggests that just as with physical health, a healthy memory requires you to use it or lose it!

\section{What should I do if I am really concerned about my memory?}

If you or your family is concerned that you may have a memory problem, you should talk to your physician. It is important to write down examples of the problems you are having. It is also important to take a friend or family member with you to the appointment to help provide information to the doctor that you may not remember.

\section{For more information}

American Academy of Neurology Foundation, www.thebrainmatters.org American Academy of Neurology, www.aan.com

The American Geriatrics Society, www.americangeriatrics.org 


\section{Neurology}

Menopause and brain function

Russel L. Thompson

Neurology 2003;61;E9-E10

DOI 10.1212/WNL.61.6.E9

This information is current as of September 22, 2003

Updated Information \&

Services

Permissions \& Licensing

Reprints including high resolution figures, can be found at:

http://n.neurology.org/content/61/6/E9.full

Information about reproducing this article in parts (figures,tables) or in its entirety can be found online at:

http://www.neurology.org/about/about_the_journal\#permissions

Information about ordering reprints can be found online:

http://n.neurology.org/subscribers/advertise

Neurology ${ }^{\circledR}$ is the official journal of the American Academy of Neurology. Published continuously since 1951, it is now a weekly with 48 issues per year. Copyright . All rights reserved. Print ISSN: 0028-3878. Online ISSN: 1526-632X.

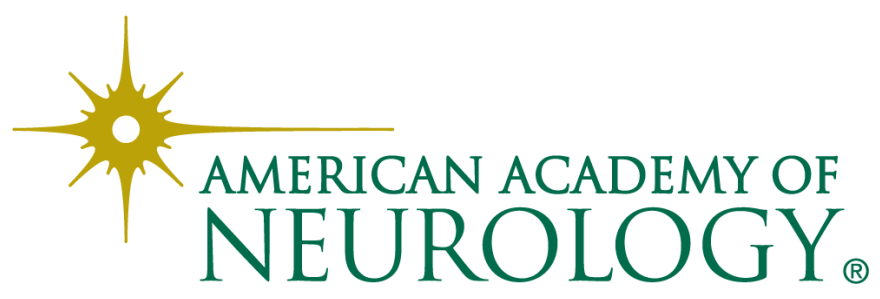

